\title{
Analisis Faktor Yang Mempengaruhi Kemauan Membayar JKN Pada Pekerja Informal Di Kulon Progo
}

\section{Factors Affecting Willingness to Pay JKN Among Informal Workers in Kulon Progo}

\author{
Irfan Helmi Nugroho, Arlina Dewi, Ietje Nazaruddin \\ Magister Administrasi Rumah Sakit, Universitas Muhammadiyah Yogyakarta \\ Email: Helminu@gmail.com, Jl. Brawijaya, Geblagan, Tamantirto, Kec. Kasihan, \\ Yogyakarta, Daerah Istimewa Yogyakarta
}

\begin{abstract}
ABSTRAK
Jumlah peserta jaminan kesehatan nasional merupakan salah satu indikator keberhasilan penyelenggaraan jaminan kesehatan nasional. Rendahnya kepesertaan jaminan kesehatan nasional yang berasal dari pekerja informal merupakan salah satu hambatan tercapainya indikator tersebut. Sehingga perlu diadakan penelitian untuk mengetahui faktor apa saja yang mempengaruhi kemauan untuk membayar jaminan kesehatan nasional pada pekerja sektor informal. Penelitian ini menggunakan metode kualitatif femonenologi dengan teknik sampling yang diambil secara purposive sampling. Subjek penelitian ini adalah 10 kepala keluarga yang bekerja pada sekor informal dan belum tergabung dalam jaminan kesehatan nasional. Hasil penelitian ini menunjukkan faktor yang mempengaruhi kemauan pekerja informal untuk membayar jaminan kesehatan naional yakni pengetahuan akan jaminan kesehatan nasional, faktor ekonomi, faktor kebutuhan mengenai perawatan kesehatan, dan memiliki persepsi negatif mengenai kualitas pelayanan kesehatan dan lembaga pengelola asuransi. Dari hasil yang ditemukan mengenai berbagai faktor yang mempengaruhi kemauan membayar jaminan kesehatan nasional pada sektor informal, dapat disimpulkan bahwa pekerja informal cenderung menunda untuk bergabung dengan jaminan kesehatan nasional.
\end{abstract}

Kata kunci: Kemauan Membayar, Asuransi Kesehatan Nasional, Pekerja Informal

\section{ABSTRACT}

National health insurance participants included as an indicator of the success of implementing national health insurance. The low participation of the national health insurance that comes from informal workers is one of the obstacles to achieving this indicator. This study examine what factors that influence the willingness to pay for national health insurance for informal workers. This study is qualitative research with phenomenological method. The subjects of this study were 10 heads of households who had not participated in the national health insurance program and worked in the informal sector. Our research reveals that the main factors that influence informal sector workers willingness to pay for national health insurance are knowledge of national health insurance, economic factors, needs of their health care, and negative perceptions about the quality of health services and health care insurance providers. Our results suggest from the various factors that influence the willingness to pay for national health insurance that informal workers tend to delay joining the national health insurance.

Keywords: Willingness To Pay, National Health Insurance, Informal Workers 
Irfan Helmi Nugroho, Arlina Dewi, Ietje Nazaruddin : Analisis Faktor Yang Mempengaruhi Membayar ...

\section{PENDAHULUAN}

Kesehatan merupakan hak setiap individu. Pemerintah menerapkan program Jaminan Kesehatan Nasional (JKN) yang merupakan jawaban dari permasalahan untuk mengatasi berbagai risiko penyakit tanpa adanya hambatan financial mulai 1 Januari 2014 (Kementrian Kesehatan, 2011). Jumlah anggota jaminan kesehatan nasional merupakan salah satu indikator keberhasilan penyelenggaraan jaminan kesehatan nasional. Program jaminan kesehatan nasional memiliki target dapat menjamin kesehatan seluruh penduduk Indonesia pada tahun 2019 dengan perkiran jumlah penduduk sebesar 257.5 juta jiwa (Mundiharno dan Thabrany, 2012).

Keanggotaan jaminan kesehatan nasional untuk Penerima Bantuan Iuran (PBI), Non-Penerima Bantuan Iuran (Non-PBI) sektor formal dan untuk pegawai pemerintah sudah memiliki aturan yang tetap. Namun, belum ada kebijakan khusus untuk dapat memastikan semua pekerja informal terdaftar sebagai anggota jaminan kesehatan nasional. Data BPJS Kesehatan pada akhir trimester pertama tahun 2018 menunjukkan bahwa total jumlah peserta jaminan kesehatan nasional sebanyak 193.535.881 jiwa dengan jenis kepesertaan penerima bantuan iuran (PBI) adalah kepesertaan yang paling banyak di Indonesia, berbeda dengan jenis kepesertaan non PBI. Jenis kepesertaan non PBI untuk peserta bukan pekerja sejumlah 5.031.849 jiwa atau 2,6\% dari total kepesertaan dan pekerja bukan penerima upah (PBPU) memiliki jumlah 26.473.159 atau sebanyak 13,67\% (BPJS Kesehatan, 2018). Jumlah penduduk Indonesia yang bekeja menurut Badan Pusat Statistik sebanyak 128,06 juta penduduk pada Tahun 2016. Dengan $57,03 \%$ atau sejumlah 69,02 juta orang penduduk bekerja dalam sektor informal. Peningkatan jumlah penduduk yang bekerja di Indonesia tefokus pada sektor industri, sektor perdagangan dan sektor jasa kemasyarakatan (Badan Pusat Statistik, 2017).

Salah satu masalah di kawasan Asia Timur dan Asian Tenggara adalah rendahnya partisipasi dalam program jaminan kesehatan nasional segingga target kepesertaan untuk mencapai 100\% partisipan sulit tercapai (Chu, et al., 2019). Di Indonesia cakupan kepesertaan yang berasal dari pekerja informal merupakan sebuah tantangan agar target kepesertaan program jaminan kesehatan dapat tercapai. Sehingga keanggotaan pekerja sektor informal harus mendapatkan perhatian khusus (Oktora, 2017).

Penelitian yang dilakukan di Sudan menunjukkan faktor yang mempengaruhi kemauan membayar asuransi adalah kesadaran mengenai asuransi, sumber pendapatan alternatif, ukuran rumah tangga, pertanggungan asuransi, kepemilikan aset rumah tangga dan agama (Basaza et al., 2017). Penelitian lain di Vietnam mendukung pemahaman 
mengenai asuransi kesehatan yang tinggi dapat meningkatkan kemauan untuk membayar iuran asuransi (Nguyen dan Hoang, 2017). Semakin besar jumlah keluarga, semakin tinggi tingkat pendidikan dan semakin tinggi pendapatan dihubungkan dengan meningkatnya keinginan untuk membayar asuransi, namun semakin bertambah usia menunjukkan berkurangnya kemauan untuk membayar asuansi. (Nosratnejad et al., 2016).

Beberapa faktor yang menghambat tercapainya kepesertaan jaminan kesehatan nasional di Cina adalah kurangnya manfaat yang diberikan oleh program asuransi, terjadi ketidakadilan dalam perawatan kesehatan, perlindungan keuangan yang terbatas dan portabilitas yang buruk (Ranabhat et al., 2020). Sedangkan faktor yang membuat rendahnya keinginan untuk mengikuti jaminan kesehatan di Sudan adalah kurangnya skema mengenai asuransi, gaji yang rendah dan ketidak percayaan terhadap lembaga pengelola asuransi (Basaza et al., 2017). Kualitas pelayanan kesehatan dan letak geografis memiliki pengaruh terhadap kemauan dalam mengikuti jaminan kesehatan nasional (Dewi dan Mukti, 2018). Sebuah systematic review menemukan tingkat pendapatan yang rendah atau kurangnya sumber daya keuangan, kualitas layanan kesehatan yang buruk, sikap petugas kesehatan, waktu menunggu pasien dan efisiensi pengobatan menyebabkan rendahnya kepesertaan dari jaminan kesehatan nasional (Adebayo et al., 2015).

Berdasarkan paparan penelitian di atas yang menunjukkan fenomena rendahnya kepesertaan jaminan kesehatan nasional pada pekerja informal, peneliti melakukan penelitian kualitatif fenomenologi untuk menganalisis faktor yang mempengaruhi kemauan membayar jaminan kesehatan nasional pada pekerja sektor informal.

\section{METODE}

Penelitian ini menggunakan metode penelitian kualitatif fenomenologi. Penelitian ini menggali fenomena yang terjadi berupa pekerja informal yang belum bergabung dalam jaminan kesehatan nasional sehingga dapat ditemukan faktor yang mempengaruhi kemauan untuk membayar jaminan kesehatan nasional oleh pekerja sektor informal. Penelitian dilakukan pada bulan November 2018 di Desa Banaran Kecamatan Galur untuk daerah rural dan Desa Wates Kecamatan Wates, Kabupaten Kulon progo untuk daerah urban sesuai dengan Peraturan Badan Pusat Statistik Nomer 37 Tahun 2010 Tentang Klasifikasi Perkotaan Dan Perdesaan Di Indonesia (Badan Pusat Statistik, 2010). Data dalam penelitian ini didapatkan infroman yang dipilih menggunakan metode puposive sampling dengan kriteria informan merupakan seorang kepala keluarga, belum terdaftar dalam jaminan kesehatan nasional, bekerja pada sektor informal dan tinggal di 
Irfan Helmi Nugroho, Arlina Dewi, Ietje Nazaruddin : Analisis Faktor Yang Mempengaruhi Membayar ...

daerah urban dan rural. Total didapatkan 10 informan setelah sampel sampai pada titik jenuh dimana tidak mendapatkan informasi baru atau tidak lagi memperoleh wawasan baru.

Pengumpulan data pada penelitian ini dilakukan dengan teknik wawancara mendalam semi terstruktur. Pertanyaan wawancara diberikan untuk mengetahui karakteristik informan dan faktor yang mempengaruhi kemauan membayar jaminan kesehatan nasional. Pengumpulan data dilakukan di tempat-tempat yang nyaman bagi informan yakni rumah informan. Perekam suara digunakan untuk merekam wawancara dan catatan dibuat agar observasi berjalan secara relevan. Anonimitas informan dipastikan dengan menggunakan nama kode informan bukan nama sebenarnya. Data yang didapatkan diolah menggunakan analisis deskriptif dengan proses analisis data berupa reduksi data, display data dan penarikan kesimpulan dan verifikasi. Uji validitas dan reliabilitas menggunakan prinsip credibility, transferability, dependability dan confirmability. Kode kategori dan tema ditemukan dan menjadi dasar analisis. Pernyataan informan kemudian disajikan dalam bentuk kutipan.

\section{HASIL}

Karakteristik informan yang tersaji pada Tabel 1 menunjukkan bahwa seluruh informan sejumlah 10 orang dimana 5 informan tinggal di daerah urban dan 5 informan tinggal di daerah rural. Seluruh informan merupakan seorang kepala keluarga yang berjenis kelamin laki-laki. Terdapat 3 informan dengan anggota keluaraga sejumlah 2 orang, 3 informan memiliki 3 orang anggota keluarga dan 4 informan dengan 4 anggota keluarga. Usia Informan yang paling muda yaitu berumur 24 tahun dan usia paling tua yaitu 40 tahun.

Tabel 1. Karakteristik Informan

\begin{tabular}{ccccc}
\hline Informan & Usia & Jenis Kelamin & $\begin{array}{c}\text { Anggota } \\
\text { keluarga }\end{array}$ & Daerah \\
\hline 1 & 25 & Pria & 2 & Urban \\
2 & 33 & Pria & 3 & Urban \\
3 & 26 & Pria & 2 & Urban \\
4 & 35 & Pria & 4 & Urban \\
5 & 31 & Pria & 4 & Urban \\
6 & 36 & Pria & 3 & Rural \\
7 & 28 & Pria & 3 & Rural \\
8 & 32 & Pria & 4 & Rural \\
9 & 24 & Pria & 2 & Rural \\
10 & 40 & Pria & 4 & Rural \\
\hline
\end{tabular}


Penelitian ini bertujuan untuk untuk mengetahui secara dalam mengenai pengambilan keputusan dalam kemauan untuk membayar jaminan kesehatan nasional. Dari hasil wawancara, didapatkan beberapa hal yang dapat dikelompokkan menjadi 4 kelompok besar yaitu: pengetahuan mengenai jaminan kesehatan nasional, faktor ekonomi, kebutuhan mengenai perawatan kesehatan, dan persepsi mengenai kualitas pelayanan kesehatan dan lembaga pengelola asuransi.

Pengetahuan yang baik dan buruk terhadap jaminan kesehatan nasional secara umum sama-sama dimiliki oleh informan yang berada di daerah urban maupun rural. Pengatahuan yang baik mengenai jaminan kesehatan nasional ditunjukkan mengenai pemahaman akan jaminan kesehatan nasional merupakan sebuah asuransi kesehatan, penyelenggara adalah pemerintah, memiliki manfaat pelayanan kesehatan gratis, bersifat diwajibkan dan mengetahui mengenai jenis kepesertaan, kelas mapun syarat mendaftar jaminan kesehatan nasional. Salah seorang informan mengatakan:

"BPJS ya, itu kan kaya ini ya mas kaya askes gitu ya kan, asuransi kesehatan. Kalau tidak salah harusnya diwajibkan buat semua warga Indonesia ya katanya tahun 2019...saratnya saya malah udah tau mas, kemarin nanyananya ke temen. Kaya KK, KTP, Akte kelahiran gitu-gitu kan mas ya mas...” (Informan 1)

"Jadi BPJS menurut saya yaaa semacam asuransi kesehatan, pas kita dapat musibah kita jadi dapat keringanan biaya seperti itu sih. Ketika sakit dapat keringanan" (Informan 2)

"BPJS setahu saya ya, itu to kalau kerja PNS dapet kartu BPJS atau BPJS yang dari pemerintah itu yang gak bayar atau istilahnya jamkesmas ya? Sama kalau ada yang bayar sendiri. Benar nggak pak? Nanti kalau ikut BPJS ke puskesmasnya gak bayar kalau berobat” (Informan 6)

Pengetahuan buruk dapat dilihat dari informan yang tidak mengetahui penyelenggara dari jaminan kesehatan nasioanal, tidak mengetahui kelas BPJS, tidak mengetahui kepesertaan, kewajiban mengikuti, sarat mengikuti dan premi dari jaminan kesehatan nasional. Seperti yang diungkapkan salah satu informan:

"Yang aku tahu? Ngga, ngga tahu gimana daftarnya aja ga tahu gimana. Belum tahu aku." (Informan 3)

Faktor ekonomi merupakan salah satu faktor yang berpengaruh terhadap kemauan pekerja sektor informal untuk mengikuti jaminan kesehatan nasional. Faktor ekonomi yang ditemukan pada daerah urban maupun rural yang mempengaruhi kemauan mengikuti jaminan kesehatan nasional adalah penghasilan yang dinilai tidak banyak dan tidak menentu tiap bulan, tidak keberatan dengan sistem out of pocket dan memiliki tabungan kesehatan. Hasil wawancara terhadap informan mendapatkan hasil sebagai 
Irfan Helmi Nugroho, Arlina Dewi, Ietje Nazaruddin : Analisis Faktor Yang Mempengaruhi Membayar ...

berikut:

“...kan saya ga tentu ya penghasilannya perbulan pak, jadi ya belum pengen aja buat daftarin keluarga.”(Informan 6)

"Wah berat ya mas, soalnya untuk pemasukan aja ga seberapa hehehehehe ya tadi mas kan jarang butuh ya mas. Jadi hehehe untuk menyisihkan perbulan ya berat ya mas." (Informan 2)

Dua dari lima informan yang tinggal di daerah rural mengatakan belum tertarik mengikuti BPJS dikarenakan tidak keberatan dengan membayar pelayan kesehatan setiap kali kedatangan atau out of pocket.

"Belum ada mas, saya merasa cukup seperti ini tiap bulan. Ya cukup, tidak memberatkan membayarnya" (Informan 10)

"Hahaha iyaa saya keluar duit buat berobat aja gapapa mas" (Informan 8)

Kebutuhan mengenai perawatan kesehatan menjadi salah satu faktor yang berpengaruh terhadap kemauan pekerja sektor informal untuk mengikuti jaminan kesehatan nasional. Baik informan yang berada di daerah urban dan rural merasa tidak membutuhkan perawatan kesehatan dikarenakan jarang sakit, tidak memiliki riwayat penyakit berat dan apabila informan jatuh sakit, sakit yang diderita tidak berat. Hasil wawancara dengan salah satu informan mendapatkan hasil:

"Jarang mas, paling batuk pilek flu biasa gitu mas, itu aja yaa hmmm kira-kira tiga bulan sekali ya dan minum obat sendiri juga sembuh” (Informan 1)

"Jarang, keluarga kita jarang sakit, paling kalo anak panas-panas pake cara herbal aja nanti sembuh. Paling setahun dua kali flu demam nanti beli obat di apotek sendiri. Ya gak berharap sakit juga, doa yang baik-baik”(Informan 9)

Terdapat satu dari sepuluh informan yang membutuhkan pelayanan kesehatan rutin tiap bulan.

"Anak ndak sih, paling sakit ya sekali dua kali pilek batuk biasa. Cuma saya yang butuh rumah sakit tiap bulan, saya sakit diabetes.” (Informan 10)

Persepsi terhadap kualitas pelayanan kesehatan dan penyelenggara jaminan kesehatan nasional umumnya sama pada daerah urban dan rural. Terdapat dua persepsi mengenai kualitas pelayanan kesehatan yakni persepsi positif dan persepsi negatif. Informan yang memiliki persepsi negatif terhadap kualitas pelayanan kesehatan merasa bahwa pelayanan kesehatan umum dinilai lebih baik dibandingkan pelayanan terhadap pasien dengan BPJS, mengurus rujukan dirasa merepotkan dan antrian pelayanan kesehatan yang dinilai lama.

"Dari masuk rumah sakit mas, bagi orang awam ditanya pak pake jaminan ndak, kalau jaminan pripun kalo umum pripun? Kalo jaminan harus kesana-kesana kalo umum langsung masuk. Ya itu bawa surat rujukan kan harus ke puskesmas dulu repot ya, lebih enak kalau langsung kerumah sakit aja. Dulu juga pernah nganter adek ke PKU itu langsung umum cepet masuk, kalo pake jaminan antrinnya lama” (Informan 10)

“...banyak di RS lebih cepat yang ga pake BPJS, terus dari segi obat lebih baik 
yang ga pake BPJS to. Pelayanan dipendaftarnya sempet ditanya kan loket umum sma bpjs disendiriin, kalo langsung bayar ambil obatnya cepet, kalo bpjs lama." (Informan 9)

Persepsi negatif juga dirasakan informan dikarenakan BPJS tidak mengklaim semua penyakit yang diderita, seperti yang dikatakan informan sebagai berikut:

“Sakitnya kayanya ya, gak semua dibayar BPJS” (Informan 8)

Persepsi terhadap lembaga pengelola asuransi juga menjadi salah satu faktor yang berpengaruh terhadap kemauan pekerja sektor informal dalam mengikuti jaminan kesehatan nasional. Informan merasa berita mengenai hutang BPJS, tunggakan iuaran oleh peserta, BPJS dinilai kurang sosialisasi, kesulitan saat mendaftar BPJS dan pembayaran iuran BPJS dan menganggap asuransi swasta lebih baik dibanding BPJS berpengaruh dalam mengikuti jaminan kesehatan nasional. Hasil wawancara terhadap informan mendapatkan hasil sebagai berikut:

“...menurut saya BPJS yang kurang sosialisasi ya mas, jadi keuntungannya apa aja, kan kita udah bayar ni, masak ga ada promosinya. Sarat-saratnya juga belum tau. Fitur-fiturnya apa aja selain ga bayar kalo sakit...kalo mau ngurus ga ribet mas, ga perlu kesana-sini rujuk sana-sini. Kan kita juga yang bayar.” (Informan 2)

Informan yang memiliki persepsi positif merasa bahwa pelayanan kesehatan umum dinilai sama baiknya dengan pelayanan terhadap pasien dengan BPJS. Senada dengan jawaban dari salah satu informan sebagai berikut:

"...sedenger saya sih hmmmm baik-baik aja sih mas. Dengar-dengar sih baikbaik saja. Tapi harus ngurus-ngurus gitu ya kalo ke rumah sakit tapi wajar ya mas." (Informan 1)

\section{PEMBAHASAN}

Pengetahuan yang baik maupun buruk terhadap jaminan kesehatan nasional ditemukan merata pada informan yang berada di daerah urban maupun rural. Pengetahuan mengenai manfaat mengikuti asuransi nasional memiliki hubungan terhadap kemauan untuk mengikuti asuransi kesehatan nasional. Hal ini didukung oleh penelitian yang dilakukan di Vietnam dengan hasil pemahaman yang baik mengenai asuransi kesehatan meningkatkan kesanggupan serseorang untuk mengikuti dan membayar iuran asuransi tersebut (Nguyen dan Hoang, 2017). Semakin tinggi pengetahuan terhadap manfaat asuransi dan mengetahui mengenai prosedur pendaftaran asuransi kesehatan nasional semakin meningkatkan keinginan untuk membayar asuransi kesehatan dan semakin rendah pengetahuan mengenai manfaat dari mengikuti jaminan kesehatan nasional menyebabkan pemahaman yang buruk tentang pentingnya jaminan kesehatan sehingga mengurangi kemauan seseorang untuk mengikuti jaminan kesehatan nasional (Oktora, 
Irfan Helmi Nugroho, Arlina Dewi, Ietje Nazaruddin : Analisis Faktor Yang Mempengaruhi Membayar ...

2017). Tingkat pendidikan seseorang mempengaruhi mempengaruhi persepsi dalam memahami risiko apabila sakit, tingkat keengganan untuk menerima risiko, dan persepsi sejauh mana kerugian akibat sakit (Lofgren et al., 2008).

Tingkat kesadaran terhadap pentingnya mengikuti jaminan kesehatan tidak menjamin seseoang untuk bergabung dengan program jaminan kesehatan nasional. Hal tersebut disebabkan oleh persepsi akan rumitnya prosedur kepesertaan, terdapat indikasi diskriminasi pada pelayanan yang dilakukan, rujukan yang dinilai masih rumit, jumlah dan kualitas fasilitas kesehatan yang dinilai masih belum memadai, dan beberapa pertimbangan mengenai prosedural lainnya (Siswoyo et al. 2015).

Hampir semua informan mengatakan memiliki pendapatan bulanan yang rendah dan pendapatan yang tidak menentu. Pendapatan yang rendah dan tidak menentu tiap bulan memiliki pengaruh terhadap keinginan pekerja informan dalam mengikuti jaminan kesehatan nasional. Seseorang dengan penghasilan bulanan yang tinggi lebih mau mengikuti dibandingkan seseorang dengan pendapatan yang rendah (Adams et al. 2015). Kesanggupan untuk membayar pada pekerja informal di Bangladesh didapatkan lebih tinggi pada pekerja dengan pendapatan lebih banyak dibandingkan dengan pekerja informal dengan pendapatan lebih rendah (Ahmed et al., 2016). Terdapat hubungan positif antara kesediaan untuk mengikuti jaminan kesehatan dan pendapatan yang diterima. Dengan meningkatnya pendapatan, begitu pula keinginan untuk bergabung dengan jaminan kesehatan nasional (Al-Hanawi et al., 2018). Penelitian di Makassar menunjukkan hasil bahwa pekerja informal menggunakan pendapatannya untuk memenuhi kebutuhan harian dan menunda pembayaran iuran jaminan kesehatan nasional (Marzuki et al., 2019). Pendapatan yang tidak menentu setiap bulan dari pekerja informal menjadikan pertimbangan utama dalam merencanakan pengeluaran bulanan rumah tangga termasuk apabila harus membayar iuran kepesertaan jaminan kesehatan nasional setiap bulan (Oktora, 2017).

Alasan belum ingin bergabung dengan jaminan kesehatan nasional juga disebabkan informan tidak keberatan dengan biaya out of pocket atau membayarkan sejumlah uang setiap kali mendapatkan pelauanan kesehatan. Pembayaran out of pocket dilakukan di penyedia layanan kesehatan swasta dikarenakan infrastruktur kesehatan dan kualitas layanan yang lebih baik dibandungkan pelayanan kesehatan milik pemerintah (Nemati et al., 2019). Senada dengan penelitian di Iran yang mengatakan bahwa ketidakpuasan terhadap layanan di bagian publik, inefisiensi dalam mekanisme jaminan kesehatan sosial, dan kurangnya layanan terorganisir di rumah sakit umum juga menjadi 
alasan tingginya pembayaran out of pocket (Abolhallaje et al., 2013). Pembayaran pelayanan kesehatan secara out of pocket dapat menjadi beban ekonomi terutama di rumah tangga miskin. Dengan mengurangi ketergantungan sistem kesehatan pada pembayaran langsung dan memberikan lebih banyak perlindungan risiko finansial. (Shet et al. 2018)

Salah satu faktor yang mempengaruhi rendahnya kemauan untuk mengikuti jaminan kesehatan nasional karena informan jarang sakit, sakit yang diderita bukan sakit berat, tidak memiliki riwayat penyakit kronis dan hanya satu informan yang memiliki riwayat sakit kronis dan membutuhkan perawatan rutin setiap bulan. Orang dengan riwayat penyakit kronis di Vietnam memiliki kemauan yang lebih tinggi untuk mengikuti dan membayar lebih banyak dibandingkan dengan orang yang tidak memiliki riwayat penyakit kronis (Huyen dan Minh 2014). Semakin banyak anggota keluarga yang memiliki penyakit kronis semakin tinggi pula kesanggupan untuk mengikuti jaminan kesehatan nasional (Dror et al., 2016). Penelitian di Vietnam menyatakan bahwa kesanggupan untuk membayar dan mengikuti jaminan kesehatan nasional ditemukan pada rumah tangga yang memiliki minimal satu anggota dengan riwayat penyakit kronis. Tingginya kesanggupan tersebut dikarenakan anggota keluarga yang memiliki riwayat penyakit kronis memiliki kebutuhan rutin akan layanan kesehatan (Lofgren et al., 2008). Penelitian di Makassar menunjukkan bahwa terdapat risk taker atau orang yang merasa jarang sakit akan cenderung tidak mempunyai kemauan untuk bergabung dalam jaminan kesehatan nasional dan didominasi oleh usia muda (Abadi et al., 2019).

Seseorang dengan pengalaman mendapatkan pelayanan kesehatan di rumah sakit dalam satu tahun terakhir memiliki kecenderungan untuk mau membayar jaminan kesehatan nasional lebih banyak dibandingkan dengan yang belum pernah dirawat di rumah sakit (Ghosh dan Mondal, 2011). Berbeda dengan penelitian yang dilakukan di Arab Saudi yang mendapatkan hasil bahwa rumah tangga dengan anggotanya yang menderita penyakit kronis tidak memiliki hubungan dengan kemauan untuk bergabung dan untuk membayar iuran jaminan kesehatan nasional (Al-Hanawi et al., 2018). Rumah tangga yang memiliki anggota keluarga dengan penyakit kronis kurang bersedia untuk membayar asuransi dikarenakan pengalaman yang tidak menyenangkan akan pelayanan medis sebelumnya (Adebayo et al., 2015). Riwayat penyakit kronis tidak memiliki pengaruh terhadap keinginan untuk bergabung dalam jaminan kesehatan nasional dikarenakan responden memilih untuk pergi kepelayanan kesehatan yang murah dibandingkan harus membayar jaminan kesehatan bulanan (Oktora, 2017). 
Irfan Helmi Nugroho, Arlina Dewi, Ietje Nazaruddin : Analisis Faktor Yang Mempengaruhi Membayar ...

Persepsi terhadap kualitas pelayanan kesehatan memiliki pengaruh terhadap kemauan dalam mengikuti jaminan kesehatan nasional. Penelitian di Arab Saudi mendapatkan hasil bahwa seseorang yang merasa puas terhadap kualitas dari penyedia pelayanan kesehatan lebih ingin bergabung terhadap jaminan kesehatan nasional dibandingkan orang yang tidak puas terhadap pelayanan fasilitas kesehatan (Al-Hanawi et al. 2018). Kemauan untuk mengikuti jaminan kesehatan nasional didapatkan meningkat apabila pelayanan kesehatan yang didapatkan tanpa antrian lama dan kualitas pelayanan kesehatan baik (Mershed, et al. 2012). Kualitas pelayanan kesehatan yang baik termasuk semakin dekat jarak antara rumah terhadap pelayanan kesehatan memiliki pengaruh positif terhadap kemauan dalam mengikuti jaminan kesehatan nasional (Dewi dan Mukti, 2018).

Persepsi negatif menyebabkan rendahnya kemauan untuk bergabung dengan jaminan kesehatan nasional. Persepsi tersebut meliputi peresepan obat yang berlebihan, waktu antrian yang dinilai lama, perbedaan terapi antar pasien, sikap dari tenaga kesehatan, dan ketidakmampuan teknis pelayanan oleh tenaga kesehatan. Persepsi positif akan meningkatkan kemauan untuk bergabung. Persepsi positif yang dimaksud merupakan kualitas pelayan kesehatan yang diterima dinilai baik (Adebayo et al. 2015).

Persepsi terhadap lembaga pengelola asuransi juga menjadi salah satu faktor yang berpengaruh terhadap kemauan pekerja sektor informal dalam mengikuti jaminan kesehatan nasional. Penelitian yang dilakukan oleh di Sudan mendapatkan hasil ketidakmauan mengikuti jaminan kesehatan nasional disebabkan oleh tidak mendapatkan informasi mengenai asuransi yang adekuat, kejadian korupsi, ketidak percayaan dan pengalaman yang buruk dari penyelenggara jaminan kesehatan nasional (Basaza et al. 2017).

Berbeda dengan hasil penelitian yang dilakukan di St.Vincent dengan hasil orang yang merasa puas dengan sistem kesehatan yang berlaku cenderung tidak memiliki kemauan untuk mengikuti jaminan kesehatan nasional dibandingkan dengan orang yang merasa tidak puas akan sistem kesehatan yang berlaku. Hal tersebut dikarenakan bagi orang yang tidak merasa puas dengan sistem kesehatan yang berlaku memiliki kepercayaan bahwa dengan mengikuti asuransi kesehatan adalah cara untuk dapat meningkatkan kualitas pelayanan kesehatan. Orang dengan kepuasan yang tinggi terhadap sustem kesehatan yang berlaku cenderung memiliki kepercayaan bahwa mereka telah mendapatkan apa yang mereka inginkan dari sistem kesehatan yang ada, sehingga tidak merasa berkewajiban untuk mengikuti asuransi kesehatan (Adams, et. al, 2015). 


\section{SIMPULAN}

Dari hasil yang ditemukan mengenai berbagai faktor yang mempengaruhi kemauan membayar jaminan kesehatan nasional pada sektor informal, dapat disimpulkan bahwa pekerja informal cenderung menunda untuk bergabung dengan jaminan kesehatan nasional. Dibutuhkan tindakan dari penyelenggara jaminan kesehatan nasional untuk meningkatkan pengetahuan dan kesadaran akan pentingnya bergababung dengan jaminan kesehatan nasional.

\section{UCAPAN TERIMA KASIH}

Ucapan terima kasih penulis haturkan kepada segenap civitas akademik program studi Magister Administrasi Rumah Sakit Universitas Muhammadiyah Yogyakarta, para informan serta semua pihak yang telah banyak membantu menyelesaikan penyusunan penelitian ini.

\section{DAFTAR PUSTAKA}

Abadi, Muh. Y., Marzuki, D. S., Arifin, M. A., Darmawansyah, Rahmadani, S., \& Al Fajrin, M. (2019). Analisis Kepesertaan Mandiri BPJS Kesehatan Di Sektor Informal (Studi Di Kota Makassar). http://dx.doi.org/10.29241/jmk.v5i2

Abolhallaje, M., Hasani, S., Bastani, P., Ramezanian, M., \& Kazemian, M. (2013). Determinants of Catastrophic Health Expenditure in Iran. 42, 6.

Adams, R., Chou, Y.-J., \& Pu, C. (2015). Willingness to participate and Pay for a proposed national health insurance in St. Vincent and the grenadines: A crosssectional contingent valuation approach. BMC Health Services Research, 15(1), 148. https://doi.org/10.1186/s12913-015-0806-3

Adebayo, E. F., Uthman, O. A., Wiysonge, C. S., Stern, E. A., Lamont, K. T., \& Ataguba, J. E. (2015). A systematic review of factors that affect uptake of communitybased health insurance in low-income and middle-income countries. BMC Health Services Research, 15(1), 543. https://doi.org/10.1186/s12913-015-1179-3

Ahmed, S., Hoque, M. E., Sarker, A. R., Sultana, M., Islam, Z., Gazi, R., \& Khan, J. A. M. (2016). Willingness-to-Pay for Community-Based Health Insurance among Informal Workers in Urban Bangladesh. PLOS ONE, 11(2), e0148211. https://doi.org/10.1371/journal.pone.0148211

Al-Hanawi, M. K., Vaidya, K., Alsharqi, O., \& Onwujekwe, O. (2018). Investigating the Willingness to Pay for a Contributory National Health Insurance Scheme in Saudi Arabia: A Cross-sectional Stated Preference Approach. Applied Health Economics and Health Policy, 16(2), 259-271. https://doi.org/10.1007/s40258017-0366-2

Badan Pusat Statistik. (2010). Peraturan Kepala Badan Pusat Statistik Nomor 37 Tahun 2010 Tentang Klasifikasi Perkotaan Dan Perdesaan Di Indonesia. Badan Pusat Statistik.

Badan Pusat Statistik. (2017). Agustus 2017: Tingkat Pengangguran Terbuka (TPT) sebesar $\quad 5,50 \quad$ persen. https://www.bps.go.id/pressrelease/2017/11/06/1377/agustus-2017--tingkatpengangguran-terbuka--tpt--sebesar-5-50-persen.htm 
Basaza, R., Alier, P. K., Kirabira, P., Ogubi, D., \& Lako, R. L. L. (2017). Willingness to pay for National Health Insurance Fund among public servants in Juba City, South Sudan: A contingent evaluation. International Journal for Equity in Health, 16(1). https://doi.org/10.1186/s12939-017-0650-7

BPJS Kesehatan. (2018). Jumlah Peserta JKN 1 Maret 2018. https://bpjskesehatan.go.id/bpjs/index.php/jumlahPeserta

Chu, A., Kwon, S., \& Cowley, P. (2019). Health Financing Reforms for Moving towards Universal Health Coverage in the Western Pacific Region. Health Systems \& Reform, 5(1), 32-47. https://doi.org/10.1080/23288604.2018.1544029

Dewi, A., \& Mukti, A. G. (2018). The strategy to achieve universal health coverage membership in Indonesia. Research Journal of Pharmacy and Technology, 11(5), 1774. https://doi.org/10.5958/0974-360X.2018.00329.3

Dror, D. M., Hossain, S. A. S., Majumdar, A., Pérez Koehlmoos, T. L., John, D., \& Panda, P. K. (2016). What Factors Affect Voluntary Uptake of CommunityBased Health Insurance Schemes in Low- and Middle-Income Countries? A Systematic Review and Meta-Analysis. PLOS ONE, 11(8), e0160479. https://doi.org/10.1371/journal.pone.0160479

Ghosh, S., \& Mondal, S. (2011). Morbidity, Health Expenditure and Willingness to Pay for Health Insurance amongst the Urban Poor: A Case Study. Journal of Health Management, 13(4), 419-437. https://doi.org/10.1177/097206341101300404

Huyen, D. T. T., \& Minh, H. V. (2014). Willingness to pay for health insurance among informal sector workers: A case study from Hanoi capital Vietnam. 2, 8.

Kementrian Kesehatan, RI. (2011). Undang-Undang Republik Indonesia Nomor 24 Tahun 2011 Tentang Badan Penyelenggara Jaminan Sosial. Kementrian Kesehatan RI.

Lofgren, C., Thanh, N. X., Chuc, N. T., Emmelin, A., \& Lindholm, L. (2008). People's willingness to pay for health insurance in rural Vietnam. Cost Effectiveness and Resource Allocation, 6(1), 16. https://doi.org/10.1186/1478-7547-6-16

Marzuki, D. S., Abadi, Muh. Y., Darmawansyah, Arifin, M. A., Rahmadani, S., \& Al Fajrin, M. (2019). Analisis Kemampuan Membayar Dan Kemauan Membayar Peserta PBPU JKN Di Kecamatan Tamalate Kota Makassar. http://dx.doi.org/10.29241/jmk.v5i2

Mershed, M., Busse, R., \& Ginneken, E. (2012). Healthcare financing in Syria: Satisfaction with the current system and the role of national health insurance-a qualitative study of householders' views: HEALTHCARE FINANCING IN SYRIA. The International Journal of Health Planning and Management, 27(2), 167-179. https://doi.org/10.1002/hpm.2102

Mundiharno, \& Thabrany, H. (2012). Peta Jalan Menuju Jaminan Kesehatan Nasional 2012-2019. Kementrian Kesehatan RI.

Nemati, E., Nosratnejad, S., Doshmangir, L., \& Zarea Gavgani, V. (2019). The out of pocket payments in low and middle-income countries and the affecting factors: A systematic review and meta-analysis. Bali Medical Journal, 8(3), 733. https://doi.org/10.15562/bmj.v8i3.958

Nguyen, L. H., \& Hoang, A. T. D. (2017). Willingness to Pay for Social Health Insurance in Central Vietnam. Frontiers in Public Health, 5. https://doi.org/10.3389/fpubh.2017.00089

Nosratnejad, S., Rashidian, A., \& Dror, D. M. (2016). Systematic Review of Willingness to Pay for Health Insurance in Low and Middle Income Countries. PLOS ONE, 11(6), e0157470. https://doi.org/10.1371/journal.pone.0157470 
Oktora, R. (2017). Willingness to Pay for National Health Insurance Among Motorcycle Taxi Driver in Depok City, Indonesia. 2017, 11.

Ranabhat, C. L., Jakovljevic, M., Dhimal, M., \& Kim, C.-B. (2020). Structural Factors Responsible for Universal Health Coverage in Low- and Middle-Income Countries: Results From 118 Countries. Frontiers in Public Health, 7, 414. https://doi.org/10.3389/fpubh.2019.00414.

Shet, N., Qadiri, G. J., \& Kalal, B. S. (2018). Impact of Out-Of-Pocket Health Care Financing and Health Insurance Utilization among the Population: A Systematic Review. International Journal of Health Sciences, 2, 9.

Siswoyo, B. E., Prabandari, Y., \& Hendrartini, Y. (2015). Awareness of The Informal Sector Workers Towards National Health Insurance Program in Province of Yogyakarta. 9.

\begin{tabular}{|l|l|}
\hline Submission & 01 Januari 2021 \\
\hline Review & 11 Januari -26 Februari 2021 \\
\hline Accepted & 27 Februari 2021 \\
\hline Publish & 12 April 2021 \\
\hline DOI & 10.29241/jmk.v7i1.595 \\
\hline Sinta Level & Tiga (3) Nasional Akreditasi \\
\hline
\end{tabular}

